\title{
Factor of Zoom cloud meetings: Technology adoption in the pandemic of COVID-19
}

\author{
Zulherman', Zalik Nuryana ${ }^{2}$, Astadi Pangarso ${ }^{3}$, Farah Mohamad Zain ${ }^{4}$ \\ ${ }^{1}$ Universitas Muhammadiyah Prof. DR. HAMKA, Jakarta, Indonesia \\ ${ }^{2}$ Universitas Ahmad Dahlan, Yogyakarta, Indonesia \\ ${ }^{3}$ Telkom University, Bandung, Indonesia \\ ${ }^{2}$ School of Education Science, Nanjing Normal University, China \\ ${ }^{1,4}$ Universiti Utara Malaysia, Sintok, Malaysia
}

\section{Article Info}

Article history:

Received Feb 12, 2021

Revised Jun 19, 2021

Accepted Jul 15, 2021

Keywords:

COVID-19

Learning platform

Technology adoption

Zoom cloud meetings

\begin{abstract}
The purpose of this study was to prove the factors that influence the use of online learning platforms used in the COVID-19 pandemic. This study used quantitative methods to analyze the validity and reliability of items and to test hypotheses. This study employed the theory of UTAUT2 models with several other variables. The total participants in this questionnaire were 175 people: lecturers, teachers, and students at the university and were randomly drawn. Consists of ten independent variables and one dependent variable. The findings of this study on ten hypotheses were only two accepted and eight rejected but. the authenticity of this study was never investigated about the purpose of using the Zoom platform during the COVID-19 pandemic in the context of education in Indonesia.
\end{abstract}

This is an open access article under the CC BY-SA license.

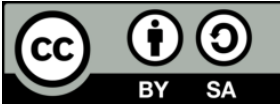

Corresponding Author:

Zulherman

Universitas Muhammadiyah Prof. DR. HAMKA

Jl. Limau II, Kota Jakarta Selatan, DKI Jakarta 12130, Indonesia

Email: zulherman@uhamka.ac.id

\section{INTRODUCTION}

The whole world feels the Coronavirus (COVID-19) has a significant impact on all countries, be it social, psychological, economic, health, and all aspects of life [1]-[6]. Handling in East Asian countries in China, Japan, and South Korea has several similarities. However, each country has different governance mechanisms strong community solidarity and positive community behavior are increasing rapidly. Although the pandemic is global the response is local depending on local governance and the socio-economic and cultural context [7]. Coronavirus epidemic of a new type of COVID-19 is still panic in the world community [8]. The number of infected cases mortality rates until the patient is healed is continuing to change over time. Up to now, more than 160 countries have reported COVID-19 positive case findings [9]. Based on data from WHO dated March 24, 2020, the infected amount is 334,981, died of 14,652, then 190 countries affected by the coronavirus epidemic. Coronaviruses are well known to be particularly resilient in terms of where they can survive. Human coronaviruses will remain an inanimate infection for nine days [10]. Indonesia, including the conditions unprotected from the stairs Corona until March 23, 2020, is still recorded the amount of 579 and died of 49 . The number of cases corona in this Indonesia is increased every day.

We have been known that the impact of COVID-19 is felt by the education world. This has been recognized by the United Nations Educational Scientific and Cultural Organization (UNESCO). UNESCO is organizing a virtual meeting of Multidimensional Education Platform on the Educational Response to 
COVID-19 [11]. The coronavirus epidemic has impacted the education sector. In the estimate, 300 million students are interrupted by their school activities around the world and are threatened with their future education rights. Some schools and universities have been temporarily laid off in their educational activities. In Indonesia, the educational world also feels its impact. A wide range of comparative Foreign Studies Program activities (overseas) should be canceled. Indonesia is a country that has the potential to become a developed and sovereign country in 2030 and this requires an important role in education, especially higher education [12]. The most important element in higher education is the learning activities between lecturers and students. This study aims to determine the importance of student perceptions as targets and measures for the success of higher education institutions. With the outbreak of COVID-19, it has become a momentum for tertiary education in Indonesia to improve online learning through various platforms, one of which is the Zoom application.

In Indonesia, the impact of the COVID-19 epidemic will continue during the rainy season. Therefore, the education sector will be disrupted because many schools and universities are in the process of students. It is also a way to break down the COVID-19 transmission chain. The school and university give a two-week time to do online management from home so that the learning process is reached according to the plan and target. However, there will be many problems with the implementation process. Other impacts of students' mental condition will be affected by achieving students' maturity in achieving their learning objectives, both academically and psychologically. Students who have to be delayed by school closure are very likely to experience psychological trauma that makes them demoting to learning [13]. Based on that reality, education in Indonesia has begun to use online and distance learning even though in practice, it raises several problems. COVID-19 forces many people around the world to evaluate the learning process that has been carried out [14]. Long before the outbreak of COVID-19, technological developments have been very rapidly changing with the emergence of a new paradigm known as e-learning [15].

The technology acceptance model in understanding academic, behavioral intentions, shows that experience using technology functions as an important factor determining e-learning policies [16]. The use of educational technology certainly requires information on how users behave towards technology. Various educational technologies in Indonesia, require complicated and difficult uses. Lately, the Zoom application has emerged as an alternative application used by most people in the world of education. Information from the official website https://zoom.us/about. Zoom is the leader in modern enterprise video communications, with an easy, reliable cloud platform for video and audio conferencing, collaboration, chat, and webinars across mobile devices, desktops, telephones, and room systems. Zoom Rooms is the original software-based conference room solution used around the world on board, conference, huddle, and training rooms, as well as executive offices and classrooms. Founded by Eric S. Yuan in 2011, Zoom helps businesses and organizations bring their teams together in a frictionless environment to get more done. Zoom is a publicly traded company on Nasdaq (ticker: ZM) and headquartered in San Jose, California. However, during the epidemic of the COVID-19, the Indonesian government issued an online learning policy in schools and universities. Which problem will happen if the management system supports online learning implementation? We can review from the aspect of individual capability. Internet network aspect and application device used to be considered so that online learning is carried out well [17]. Then what is this online learning solution for work from home program? So, the originality of this research is that it has never been investigated about the intention to use Zoom during the COVID-19 outbreak in the context of education in Indonesia.

Zoom cloud meeting (ZCM) is a web conferencing platform based on the cloud. We can almost reach others only through visual, video, voice, or both through live chats. You can save the discussion for later viewing. Zoom Application has its core functionality [18]. You are one to one meeting, video group conferences and swapping of screens. Worldwide educators have begun to use technology-based software or "just-in-time" instructional approaches to a degree never before seen [19]. The government's implementation of social distance has a huge effect on learning practices in tertiary institutions. Colleges arrange class meetings in collaboration and home assignments with online meetings. The purpose of this study is to explain the variety of models and platforms used in social distance learning for potential teachers or University students, teachers and the lecturer of Indonesia [20]. Most cloud-based systems can be used/combined with m-learning cases. A rich pool of technologies is thus available and can easily be used in the design and delivery of cloud-based services. There are two cloud storage solutions a modular platform for the good selection and deployment of educators mobile learning applications and a versatile contextualization solution for mobile learners to enable a customized learning environment. The framework provides a flexible approach which supports teachers and lecturers in designing and automatically deploys mobile applications to enable learners to make them possess mobile device-supporting m-learning actions [21].

Online learning helps students to use resources to suit their needs. That is because online learning uses advanced modern resources. The online content delivery method in classrooms, teachers, students, interaction tools, and others in online learning is divided into two models, namely synchronous and 
asynchronous online learning. Synchronous online learning was developed due to time and sector demands, including education. There is no online physical meeting. Synchronous and asynchronous online learning models play an important role in implementing online classes such as online discussions, instant messages, and websites by replicating regular classroom learning experiences that include social relationships not only between students and teachers but also between students themselves. Synchronous online learning is direct at the same time by using well-planned instructions and generating learning-oriented interactions. This learning is therefore like presenting regular classes in online learning. Students and teachers in one room and one time engage in learning interactions [22]. This type of learning creates an online learning process as communication is established in regular classrooms. And unobstructed at one time. Classrooms, learning media, and conferences are the three main factors that influence online synchronous learning [23]. Asynchronous online learning is distinguished in different definitions because certain elements, features and facilities are generally in certain characters. Easy to understand is that the asynchronous online learning component is introduced as an unlimited interactive learning group with space and time wherever and whenever possible [24].

Asynchronous online learning is like synchronous learning which is a learning-centered procedure that requires online tools to gather the information that depends on the time place and relationship of people. Asynchronous online learning has the full role of computer-based communication (CMC) to carry out learning at anytime and anywhere through asynchronous online discussion. Asynchronous online learning is a learning-centered approach based on the constructivist theory that emphasizes the importance of direct interaction. This method integrates independent learning with asynchronous learning interactions which can be used to develop traditional, distance, and sustainable education systems [22]. A combination of student and electronic networks that serve as an asynchronous online learning network. Conditions and contributing factors are different, so it can be said to be a different component. For this reason, asynchronous learning is called learning which carries out a teaching process that is not limited to time and space [25], [26].

An analysis of the strengths, weaknesses, opportunities, and threats to ZCM is explained in this paper. ZCM is committed to delivering online learning like regular classes without space and time. Users are given access to interact as in a regular class. The weakness of ZCM lies in the different versions of the premium and non-premium versions. Non-premium users only have a 40-minute chance at each session, then leave and re-enter the room and limit 100 users to each meeting. ZCM opportunities in Indonesia are quite large as ZCM is a user-friendly and easy-to-use application making it easier for users to easily adapt using ZCM. According to some information, ZCM is at risk in terms of user privacy security, but the development team has responded to and corrected it. Overall, ZCM has a great opportunity to use in Indonesia. In the ZCM list, synchronous learning refers to a learning event in which a group of students engages in learning at the same time.

To assess the ZCM platform technology as a platform widely used by educators during online learning in a pandemic, researchers have used several models for the technology acceptance model (TAM) [27] have developed the Unity Theory of Acceptance and Use of Technology (UTAUT) through the combination of eight models of IT acceptance. UTAUT had previously four main buildings: performance expectations, social impact, efforts expectations, and conditions of facilitation that influence behavioral intention to use technology. In its development this theory was found the latest in 2012 were presented three new UTAUT Model constructs. The first building was hedonic motivation, the second was the price, and the third was a tradition [28]. He said that the proposed modifications to UTAUT2 demonstrate major variation shifts in behavioral intentions while using technology.

Performance expectancy (PE) is conceptualized "as the degree to which one assumes that the application of technology can help him or her gain profits in job results" [27]. Generally speaking, they seem to be more driven to use and adopt emerging innovations if they see that this technology is better and more practical in daily life [26], [28], [29]. The following theory articulates this study:

H1: Performance standards may affect the intention of the consumer to follow ZCM positively.

Effort expectancy (EE) is "the level of ease connected with the use of a system." In line with Venkatesh, et al. [27] and Davis [29], an individual's intention to accept a new system is not only predicted by how much the system is positively valued but also by how much using the system is not difficult and requires free effort. Therefore, because of the use of ZCM, which requires a certain level of knowledge and skills business expectations can play an important role in determining customer intentions to use these technologies [30]. The following hypotheses are taken from this study:

$\mathrm{H} 2$ : Effort expectation should have a positive effect on ZCM behavioral intent.

Social influence (SI) is described as "as much as a person believes that key events think that a new method must be employed" [27]. Furthermore the impact of peers on society greatly affects the behavior of the individual and their plan to use technology like Google Apps and iPad as a platform for interactive learning [30]-[32] and the college capture method ReWIND [33]. This research therefore proposes that: 
H3: Social impact has a beneficial effect on the intention of users to use ZCM.

Facilitating condition (FC) is pointed out as "the degree to which an individual considers the use of the program to be organizational and technological infrastructure is indicated as proof of the presence and/or other supporting requirements" [27]. Currently learning promotes the conditions that are deemed accessible through appropriate learning environments and deep infrastructure universities that can promote the use of technology. In accelerating student learning, build communication skills and peer engagement, imagination, confidence, personality, and a willingness to engage in engaging partnerships and places for fun learning [34], [35]. The following theories are derived from this discussion:

H4: Facilitating condition (FC) has a beneficial impact on the use of ZCM by users.

Hedonic motivation (HM) essentially proposed a direct correlation between hedonic motivation and consumer purpose of using technology [28]. He included, under the principle of hedonic motivation, intrinsic benefits (i.e., happiness, pleasure, playfulness, training, and enjoyment) alongside extrinsic utility (i.e., efficiency, usability, and anticipated performances). Indeed, it has been highly discussed over IS literature that intrinsic utility could play a curious role in accelerating people 's purpose to implement innovative systems). This research therefore uses the following scientific theory:

H5: Hedonic motivation (HM) will influence users positively to adopt of ZCM.

Habit $(\mathrm{H})$ is the extent to which people continue to execute repetitive learning-based behaviors [36]. It means that self-reported perception of a recurring thought process which takes place outside consciousness [37]. Venkatesh, Thong, and $\mathrm{Xu}$ [28] established two important links: habit intention and habit use. This research, therefore, examines the following hypotheses:

H6: Habit impacts behavioral intent directly and positively.

Perceived ease of use (PEoU), for ZCM, it is considered that the teachers feel that working with ZCM does not quite take more physical or mental effort. Thus, encouraging them to easily achieve their learning objectives. According to Zain, et al. [38] the original model of technology acceptance technology (TAM) [39], perceived ease of use of learning technologies has had a direct positive effect on perceived utility [40] and has meditated on the decision to use a program by academic perceived usefulness [41]. Then we suggest:

H7: The Perceived Ease of Use (PEoU) affects the behavioral intention positively and directly.

Perceived Self-Efficacy (PSE) is the understanding of teachers of the desire to use this content in the course. Regarding ZCM, the concept of instructors using effectiveness in the execution of a task is expressed. As for perceived self-efficacy, the research showed that self-efficacy was the key to understanding the use of teacher technology in teaching methods. According to survey, teachers have highly positive attitudes towards learning. including perceived self-efficacy, satisfaction, utility, and intention to use behavior [42]. In recognizing the behavioral intent of instructors in the use of e-learning environments. perceived benefit is the largest contributor (56\%). Regarding self-efficacy, we expect instructors who feel confident in teaching the ZCM to find these components more useful. And we have:

H8: Perceived self-efficacy (PSE) positively and specifically affects behavioral intent (BI) when using ZCM.

Perceived enjoyment is how instructors think that ZCM teaching is a fun, exciting, and enjoyable task. While considering intrinsic motivational variables such as perceived enjoyment, it was found that this variable plays a significant part in embracing the technology of the consumer. Likewise [43] showed that both perceived usefulness and perceived enjoyment played a significant role in influencing the attitude of students and their intention to use educational technology platforms. Within the ZCM a positive relationship may, therefore, be postulated between perceived gratification and the intention to use of ZCM. The research hypothesis is therefore defined as:

H9: ZCM's perceived satisfaction positively and explicitly affects behavioral intention (BI) using the program.

Perceived of usefulness, regarding ZCM, the perceived usefulness reflects how instructors assume that ZCM will boost their performance, easiness, and results. In addition to Davis [28], the main impact on the system use perceived usefulness was an excellent predictor of ZCM 's intention [42], academics [44], and academics [40]. We therefore suggest the following:

H10: The Perceived Utility (PU) of ZCM affects the behavioral purpose of the program positively and directly.

\section{RESEARCH METHOD}

\subsection{Data collection}

Independent and dependent variables, for this analysis, ten independent variables and one dependent were retained. Participants were 175 respondents in Indonesia schools and universities for random sampling of 26 lecturers (15\%), 57 university students (33\%), 92 teachers (53\%). The average age was 35 years old 
with 52 men (30\%) and 123 women (70\%) in gender. The value of the best solution in education in Indonesia which will be studied in research problems, lecturers, teachers, and university students will be invited to contribute to this study by providing the highest platform experience in the learning process in the COVID19 pandemic using Zoom cloud meeting. Before filling out the survey questionnaire provided by the researchers, all participants were explained the purpose of this study and the completion of the questionnaire filling procedure provided. On average each participant takes no more than 15 minutes to complete the questionnaire.

\subsection{Data analyses}

Data analysis and hypothesis have been evaluated using structural equation modeling (SEM) method for this research. The Smart PLS program Version 3.0 [45] was used to conduct this research. Despite objections, PLS is a well-known technique for evaluation of the path coefficients in structural models and due to its ability to model latent structures under conditions of non-normal and small to medium sample size has become more popular with marketing research in the past decade in general [46]. However, PLS research was performed and found to be appropriate as a single element in the study. The PLS algorithm process was used to determine the load. weight and path coefficients significance and the bootstrapping method (5000 resamples) was used to determine the hypothesis meaning levels. Following the procedure Purpose of testing the dependence structure described in the structural model, validity, and efficiency of the measurement model were estimated [47]. Eventually, the blindfolding technique (Q2) has been used to develop and assess the consistency of the hypotheses tested.

\section{RESULTS AND DISCUSSION}

Data collected and suitable for processing is then tested using Smart PLS 3.3.9. Figure 1 shows an analysis conceptual framework using Smart PLS. Data processing using the Smart PLS program sequentially consists of measurement model evaluation (outer model) and structural model evaluation (inner model) [47]. Outer models for reflective indicators consist of checking the load factor value (cut off $>=0.708$ ); the construct reliability (rho a cut off $>0.70$ ); the construct validity (AVE cut off $>0.50$ ); and the discriminant validity (HTMT cut off $<0.90$ ). The results of the calculation of the outer model are shown in Table 1.

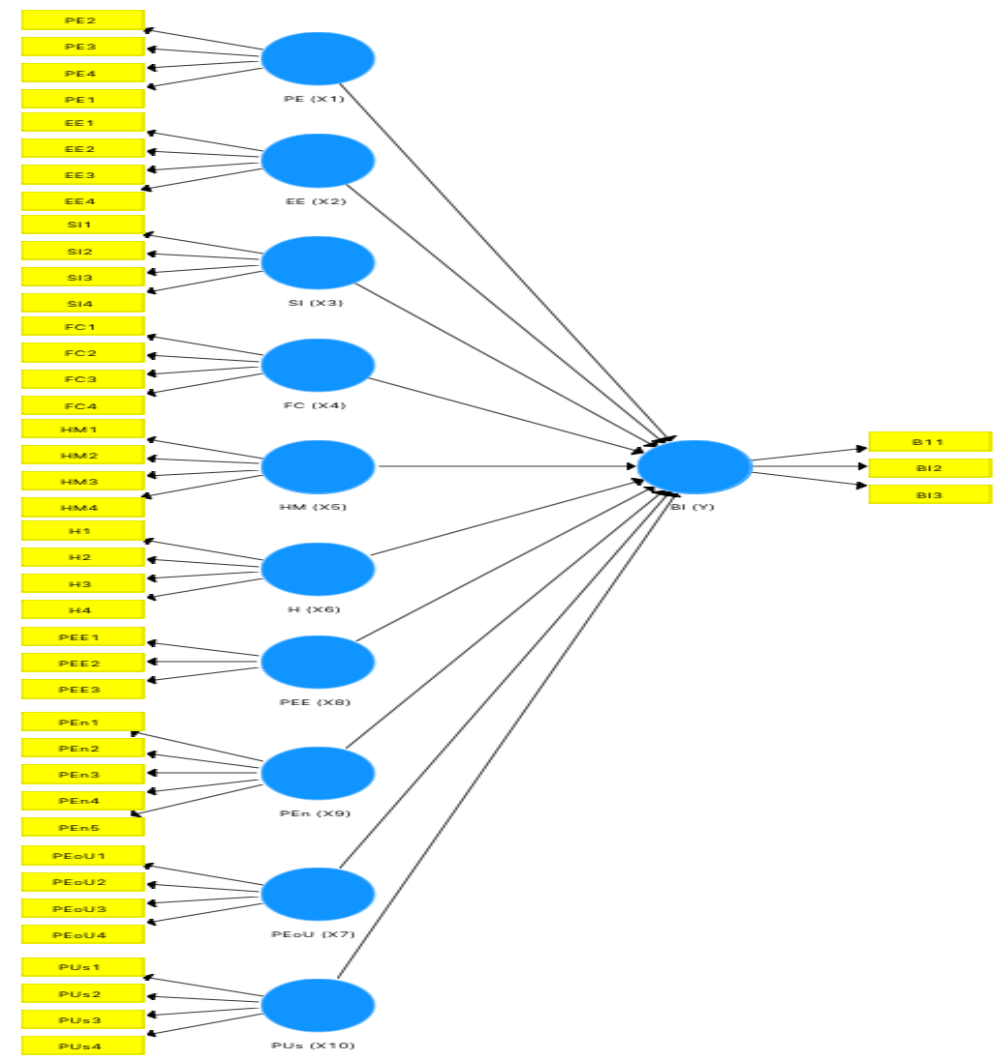

Figure 1. Smart PLS theoretical framework [48] 
Table 1. Outer model evaluation result

\begin{tabular}{|c|c|c|c|c|c|c|c|c|c|c|c|}
\hline \multirow[b]{2}{*}{ Items } & \multirow[b]{2}{*}{$\begin{array}{l}\text { Loading } \\
\text { factor }\end{array}$} & \multirow[b]{2}{*}{$\begin{array}{l}\text { Reliability } \\
\text { (rho_a) }\end{array}$} & \multirow[b]{2}{*}{$\begin{array}{c}\text { Construct } \\
\text { validity } \\
\text { (AVE) }\end{array}$} & \multicolumn{8}{|c|}{ Discriminant validity (HTMT) } \\
\hline & & & & $\begin{array}{c}\text { Behavior } \\
\text { intention } \\
(\mathrm{Y})\end{array}$ & $\begin{array}{c}\text { Behavior } \\
\text { intention } \\
(\mathrm{Y})\end{array}$ & $\begin{array}{c}\text { Behavior } \\
\text { intention } \\
(\mathrm{Y})\end{array}$ & $\begin{array}{c}\text { Behavior } \\
\text { intention } \\
(\mathrm{Y})\end{array}$ & $\begin{array}{l}\text { Behavior } \\
\text { intention } \\
(\mathrm{Y})\end{array}$ & $\begin{array}{l}\text { Behavior } \\
\text { intention } \\
(\mathrm{Y})\end{array}$ & $\begin{array}{c}\text { Behavior } \\
\text { intention } \\
(\mathrm{Y})\end{array}$ & $\begin{array}{c}\text { Behavior } \\
\text { intention } \\
(\mathrm{Y})\end{array}$ \\
\hline B11 & 0.848 & & & 0.201 & & & & & & & \\
\hline $\mathrm{BI} 2$ & 0.943 & 0.950 & 0.827 & 0.143 & 0.571 & & & & & & \\
\hline $\mathrm{BI} 3$ & 0.934 & & & 0.194 & 0.786 & 0.548 & & & & & \\
\hline EE3 & 0.959 & 0.927 & 0807 & 0.157 & 0.031 & 0.061 & 0.056 & & & & \\
\hline EE4 & 0.930 & 0.922 & 0.892 & 0.306 & 0.818 & 0.703 & 0.878 & 0.023 & & & \\
\hline FC1 & 1.000 & 1.000 & 1.000 & 0.478 & 0.288 & 0.184 & 0.149 & 0.107 & 0.246 & & \\
\hline $\mathrm{H} 1$ & 0.899 & & & 0.145 & 0.625 & 0.682 & 0.866 & 0.061 & 0.774 & 0.139 & \\
\hline $\mathrm{H} 2$ & 0.948 & 1.036 & 0.768 & 0.246 & 0.728 & 0.783 & 0.718 & 0.009 & 0.888 & 0.222 & 0.847 \\
\hline H3 & 0.773 & & & 0.201 & & & & & & & \\
\hline HM2 & 1.000 & 1.000 & 1.000 & 0.143 & 0.571 & & & & & & \\
\hline PE1 & 0.806 & & & 0.194 & 0.786 & 0.548 & & & & & \\
\hline PE2 & 0.836 & 0870 & 0880 & 0.157 & 0.031 & 0.061 & 0.056 & & & & \\
\hline PE3 & 0.851 & 0.879 & 0.880 & 0.306 & 0.818 & 0.703 & 0.878 & 0.023 & & & \\
\hline PE4 & 0.863 & & & 0.478 & 0.288 & 0.184 & 0.149 & 0.107 & 0.246 & & \\
\hline PSE2 & 1.000 & 1.000 & 1.000 & 0.145 & 0.625 & 0.682 & 0.866 & 0.061 & 0.774 & 0.139 & \\
\hline PEoU2 & 0.940 & 0864 & 0704 & 0.246 & 0.728 & 0.783 & 0.718 & 0.009 & 0.888 & 0.222 & 0.847 \\
\hline PEoU3 & 0.937 & 0.864 & 0.704 & 0.201 & & & & & & & \\
\hline SI1 & 0.794 & & & 0.143 & 0.571 & & & & & & \\
\hline SI2 & 0.796 & & & 0.194 & 0.786 & 0.548 & & & & & \\
\hline $\mathrm{SI} 3$ & 0.875 & 0.891 & 0.671 & 0.157 & 0.031 & 0.061 & 0.056 & & & & \\
\hline SI4 & 0.808 & & & 0.306 & 0.818 & 0.703 & 0.878 & 0.023 & & & \\
\hline
\end{tabular}

The data processing results for the outer model in Table 1 show that all items meet the cut-off value so that the process can continue to check the inner model. Table 1 shows the research indicators that only met the cut-off value. Researchers removed indicators that did not meet the cut off value. The loading factor value has a value of more than 0.708 indicating that the research variable can account for more than 50 percent of the variance of the indicators that cause reliability to be accepted; the reliability value is greater than 0.70 indicating that the reliability is good/satisfactory; the AVE value is greater than 0.50 , which means that the research variables can account for more than $50 \%$ of the reliability [49]. To evaluate the inner model in sequence: check the inner value of VIF (cut less than 5), the square value of $\mathrm{R}$, and the value of $\mathrm{Q}$. The processing of inner model data is done by bootstrapping 5000 samples with BCa completed by two tailored methods with a confidence interval of 0.05 . Table 2 shows the internal VIF values that already meet the cutoff. This inner VIF value of less than 5 indicates that there are no problems related to multicollinearity.

In addition, the square value of $\mathrm{R}$ is 0.290 . The square $\mathrm{R}$ shows the explanatory power of the endogenous variables (Y). R square value is categorized as weak. which means that the explanatory power of the behavioral intention variable is weak due to the total of eight variables that passed the test to the structural model. and there are only two variables that have a significant impact. An explanation of only two influential variables can be found in Table 2. The square value of Q 0.205 can be obtained from the blindfolding process. Q square cut-off value is $>0$, which means that the behavior intention variable has predictive accuracy. While the $\mathrm{Q}$ square value of 0.205 falls within the weak predictive accuracy category. The square value of $\mathrm{Q}$ can be seen in Table 2. The next step is to test the hypothesis directly that the results can be seen in Table 3. Guidelines for assessing this hypothesis can be seen in the value of $\mathrm{p}$, which must be less than 0.05 , and the statistical value of $\mathrm{T}$ must be more than 1.96 .

Table 2. Inner VIF, R square, Q square

\begin{tabular}{cccc}
\hline & Behavior intention (Y) & R square & Q square \\
\hline Behavior intention (y) & & & \\
Effort expectancy (x2) & 2.277 & & \\
Facilitating conditions (x4) & 2.389 & & \\
Habit (X6) & 4.149 & 0.290 & 0.205 \\
Hedonic motivation (x5) & 1.023 & & \\
Perceived ease of use (X7) & 4.404 & & \\
Perceived self-efficacy (x8) & 1.108 & & \\
Performance expectancy (x1) & 3.695 & & \\
Social influence (x3) & 3.740 &
\end{tabular}


Table 3 shows that the drivers of the behavioral intention to use ZCM during the COVID-19 pandemic are hedonic motivation and perceived self-efficacy. The results of the influence between variables can be seen in Figure 2. where the thicker lines have a stronger influence. Figure 3 shows that the variable $\mathrm{X}$ which has the most significant overall effect on the $\mathrm{Y}$ variable (behavior intention) is the perceived selfefficacy (X8). This is consistent with the results of the hypothesis testing and the Structural Model 4.2. which shows that perceived self-efficacy is the most significant variable affecting behavioral intent.

Based on Table 3, the results of hypothesis testing show that hedonic motivation and perceived selfefficiency have a significant influence on behavioral intent. The HM 2 indicator for the hedonic motivation variable is the only indicator of the behavioral intention variable that passes the smart PLS test. The HM2 indicator statement is "I found that using ZCM is exciting in my learning process." This shows that students get a thrilling sensation of feeling by using ZCM. This thrilling feeling is related to the enthusiasm of Zoom's learning experience during the COVID-19 outbreak. The general condition at the time of the COVID-19, in general that can be felt is also exciting. Thrilling here is exciting in the sense that the word tends to be scared. So, the learners who use the ZCM feel that they are learning with a feeling of palpitation in the 'atmosphere' of an atmosphere of fear formed by the COVID-19 outbreak. The results of the test Hypothesis 5 support the theory of UTAUT2, and previous research conducted by Venkatesh. In addition, the indicator of the perceived self-efficacy variable is PSE2 which is "I am comfortable using ZCM." This shows that the ease of use of applications has a significant effect on behavioral intent. The convenience of the ZCM application has been proven by its users to learn when the COVID-19 outbreak occurred.

Table 3. Hypothesis test

\begin{tabular}{cccccc}
\hline Hypothesis & Direct influence between variables & $\begin{array}{c}\text { Original } \\
\text { sample (O) }\end{array}$ & T statistics & p-values & Decision \\
\hline 1 & Performance expectancy (X1) -> Behavior intention (Y) & -0.180 & 1.235 & 0.217 & Not supported \\
2 & Effort expectancy (X2) -> Behavior intention (Y) & -0.130 & 1.757 & 0.079 & Not supported \\
3 & Social influence (X3) -> Behavior intention (Y) & 0.166 & 1.191 & 0.234 & Not supported \\
4 & Facilitating conditions (X4) -> Behavior intention (Y) & -0.067 & 0.720 & 0.472 & Not supported \\
5 & Hedonic motivation (X5) -> Behavior intention (Y) & -0.115 & 2.261 & 0.024 & Supported \\
6 & Habit (X6) -> Behavior intention (Y) & 0.139 & 1.074 & 0.283 & Not supported \\
7 & Perceived ease of use (X7) -> Behavior intention (Y) & 0.196 & 1.500 & 0.134 & Not supported \\
8 & Perceived self-efficacy (X8) -> Behavior intention (Y) & 0.435 & 5.099 & 0.000 & Supported \\
\hline
\end{tabular}

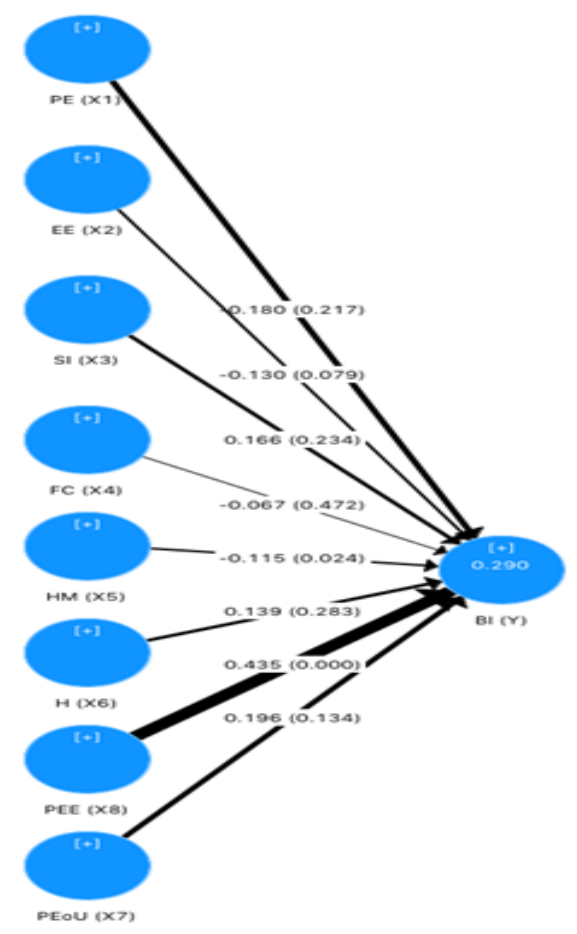

Figure 2. Inner model evaluation result [48] 


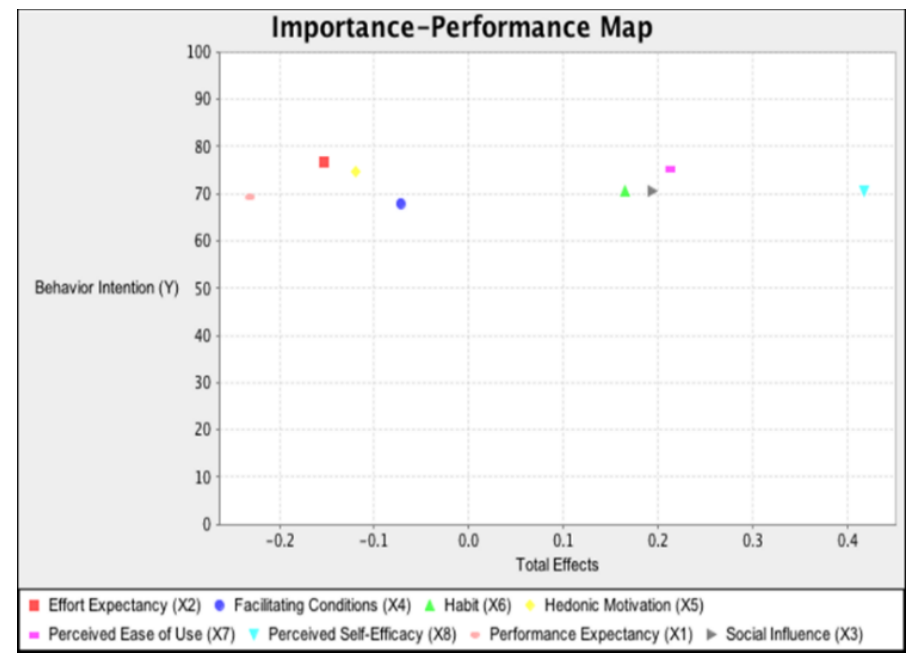

Figure 3. IPMA [48]

\section{CONCLUSION}

The results showed that the behavioral intention drivers for using the Zoom platform during the COVID-19 pandemic were hedonic motivation and perceived self-efficacy. Theoretically and practically this research contributes. The theoretical research contribution is to the theory of UTAUT2 which is demonstrated by the significant variable of hedonic motivation and perceived self-efficacy. This is supported by the theory of UTAUT2. To make a practical contribution, it is necessary to consider the user's excitement and comfort when determining the appropriate application in times of emergency/crisis. Applications for learning to be used are determined based on these two factors.

This study has several limitations, such as it is cross sectional which is tested in a certain time span that tends to be short. Furthermore, the limitation of this study is the limited number of samples so that generalizations are only in the context of the study population. There is a future research agenda including retesting possible for several hypotheses that were rejected. It is possible to conduct research in different contexts, settings, and applications (outside Zoom), so that it is expected to provide a more complete picture of various online learning applications.

\section{ACKNOWLEDGEMENTS}

The authors thank FKIP Universitas Muhammadiyah Prof. Dr. HAMKA and other universities for their help in completing the questionnaire. Thanks to elementary and secondary schools in Indonesia for their cooperation.

\section{REFERENCES}

[1] M. Cascella, M. Rajnik, A. Cuomo, S. C. Dulebohn, and R. Di Napoli, "Features, Evaluation and Treatment Coronavirus (COVID-19)," in StatPearls, Treasure Island (FL): StatPearls Publishing, 2020. [Online]. Available: https://www.ncbi.nlm.nih.gov/books/NBK554776.

[2] P. Walker, et al., "The Global Impact of COVID-19 and Strategies for Mitigation and Suppression," Imp. Coll., pp. 1-19, 2020, doi: doi.org/10.25561/77735.

[3] M. U. G. Kraemer, et al., "The effect of human mobility and control measures on the COVID-19 epidemic in China," Science, vol. 368, no. 6490, pp. 493-497, 2020, doi: 10.1126/science.abb4218.

[4] J. Torales, M. O'Higgins, J. M. Castaldelli-Maia, and A. Ventriglio, "The outbreak of COVID-19 coronavirus and its impact on global mental health,” International Journal of Social Psychiatry, vol. 66, no. 4, pp. 317-320, 2020, doi: 10.1177/0020764020915212.

[5] K. Tolksdorf, S. Buda, E. Schuler, L. H. Wieler, and W. Haas, "Influenza-associated pneumonia as reference to assess seriousness of coronavirus disease (COVID-19)," Eurosurveillance, vol. 25, no. 11, 2020, doi: 10.2807/1560-7917.ES.2020.25.11.2000258.

[6] W. Cao, et al., "The psychological impact of the COVID-19 epidemic on college students in China," Psychiatry Res., vol. 287, no. 2020, 2020, doi: 10.1016/j.psychres.2020.112934.

[7] S. Eubank, I. Eckstrand, B. Lewis, S. Venkatramanan, M. Marathe, and C. L. Barrett, Commentary on Ferguson, et al., "Impact of Non-pharmaceutical Interventions (NPIs) to Reduce COVID-19 Mortality and Healthcare Demand," Bull. Math. Biol., vol. 82, no. 4, pp. 1-7, 2020, doi: 10.1007/s11538-020-00726-x. 
[8] World Health Organization, "Report of the WHO-China Joint Mission on Coronavirus Disease 2019 (COVID-19)," 2020. [Online]. Available: https://reliefweb.int/report/china/report-who-china-joint-mission-coronavirus-disease2019-covid-19.

[9] J. R. Hageman, "The Coronavirus Disease 2019 (COVID-19)," Pediatr. Ann., vol. 49, no. 3, pp. e99-e100, 2020, doi: 10.3928/19382359-20200219-01.

[10] G. Kampf, D. Todt, S. Pfaender, and E. Steinmann, "Persistence of coronaviruses on inanimate surfaces and their inactivation with biocidal agents," J. Hosp. Infect., vol. 104, no. 3, pp. 246-251, 2020, doi: 10.1016/j.jhin.2020.01.022.

[11] UNESCO, "Multilateral Education Platform's meeting (online)," en.unesco.org, Mar. 2020.

[12] A. Pangarso, E. S. Astuti, K. Raharjo, and T. W. Afrianty, "The impact of absorptive capacity and innovation ambidexterity on sustainable competitive advantage: the case of Indonesian higher education," Entrep. Sustain. Issues, vol. 7, no. 3, pp. 2436-2455, Mar. 2020, doi: 10.9770/jesi.2020.7.3(65).

[13] R. Rusli, A. Rahman, and H. Abdullah, "Student perception data on online learning using heutagogy approach in the Faculty of Mathematics and Natural Sciences of Universitas Negeri Makassar, Indonesia," Data Br., vol. 29, 2020, doi: 10.1016/j.dib.2020.105152.

[14] J. B. Stambough, et al., "The Past, Present, and Future of Orthopedic Education: Lessons Learned From the COVID-19 Pandemic,” J. Arthroplasty, vol. 35, no. 7, pp. S60-S64, 2020, doi: 10.1016/j.arth.2020.04.032.

[15] D. F. Radcliffe, "Technological and pedagogical convergence between work-based and campus-based learning," Educ. Technol. Soc., vol. 5, no. 2, pp. 54-59, 2002.

[16] S. Alharbi and S. Drew, "Using the Technology Acceptance Model in Understanding Academics' Behavioural Intention to Use Learning Management Systems," Int. J. Adv. Comput. Sci. Appl., vol. 5, no. 1, pp. 143-155, 2014, doi: 10.14569/IJACSA.2014.050120.

[17] A. Ergün and G. Kiyici, "The Effect of Design Based Science Education Applications of Science Teacher Candidates on Their Perceptions of Engineering Education and Engineer," Pegem J. Educ. Instr., vol. 9, no. 4, pp. 1031-1062, 2019.

[18] K. Mahalakshmi and R. Radha, "Covid 19: a Massive Exposure Towards Web Based Learning," J. Xidian Univ., vol. 14, no. 4, pp. 2405-2411, 2020, doi: 10.37896/jxu14.4/266.

[19] D. Kumar and Rajasekhar, "Too much but less effective: Managing the cognitive load while designing the distance learning instructional formats," J. Adv. Med. Educ. Prof., vol. 8, no. 2, pp. 107-108, 2020, doi: 10.30476/jamp.2020.85990.1208.

[20] G. Gunawan, N. M. Y. Suranti, and F. Fathoroni, "Variations of Models and Learning Platforms for Prospective Teachers During the COVID-19 Pandemic Period," Indones. J. Teach. Educ., vol. 1, no. 2, pp. 61-70, 2020.

[21] H. T. Zimmerman, S. M. Land, and Y. J. Jung, "Mobile, Ubiquitous, and Pervasive Learning," Adv. Intell. Syst. Comput., vol. 406, pp. 101-119, 2016, doi: 10.1007/978-3-319-26518-6.

[22] M. M. Shahabadi and M. Uplane, "Synchronous and Asynchronous e-learning Styles and Academic Performance of e-learners," Procedia - Soc. Behav. Sci., pp. 129-138, 2015, doi: 10.1016/j.sbspro.2015.01.453.

[23] K. Hyder, A. Kwinn, R. Miazga, and M. Murray, The elearning Guild's Handbook on Synchronous e-Learning. The eLearning Guild, 2007. [Online]. Available: https://www.learningguild.com/pdf/4/synchronousbook.pdf.

[24] F. Mayadas, "Asynchronous Learning Networks: A Sloan Foundation Perspective," Online Learn., vol. 1, no. 1, pp. 1-16, Mar. 2019, doi: 10.24059/olj.v1i1.1941.

[25] B. Khan, Flexible Learning in an Information Society. IGI Global, 2007.

[26] B. Khan, Managing E-Learning Strategies: Design, Delivery, Implementation and Evaluation. IGI Global, 2005.

[27] V. Venkatesh, M. G. Morris, G. B. Davis, and F. D. Davis, "User acceptance of information technology: Toward a Unified View," MIS Q., vol. 27, no. 3, pp. 425-478, 2003.

[28] V. Venkatesh, J. Y. L. Thong, and X. Xu, "Consumer acceptance and use of information technology: Extending the unified theory of acceptance and use of technology," MIS Q. Manag. Inf. Syst., vol 36, no. 1, pp. 157-178, 2012, doi: $10.2307 / 41410412$.

[29] F. D. Davis, "Perceived usefulness, perceived ease of use, and user acceptance of information technology," $M I S Q$. Manag. Inf. Syst., vol. 13, no. 3, pp. 319-340, 1989, doi: 10.2307/249008.

[30] A. A. Alalwan, Y. K. Dwivedi, N. P. Rana, B. Lal, and M. D. Williams, "Consumer adoption of Internet banking in Jordan: Examining the role of hedonic motivation, habit, self-efficacy and trust," J. Financ. Serv. Mark., vol. 20, no. 2, pp. 145-157, 2015, doi: 10.1057/fsm.2015.5.

[31] R. Cheung and D. Vogel, "Predicting user acceptance of collaborative technologies: An extension of the technology acceptance model for e-learning," Comput. Educ., vol. 63, pp. 160-175, 2013, doi: 10.1016/j.compedu.2012.12.003.

[32] G. Falloon and E. Khoo, "Exploring young students' talk in iPad-supported collaborative learning environments," Comput. Educ., vol. 77, pp. 13-28, 2014, doi: 10.1016/j.compedu.2014.04.008.

[33] P. K. Nair, F. Ali, and L. C. Leong, "Factors affecting acceptance and use of ReWIND: Validating the extended unified theory of acceptance and use of technology," Interact. Technol. Smart Educ., vol. 12, no. 3, pp. 183-201, 2015, doi: 10.1108/ITSE-02-2015-0001.

[34] Y. T. C. Yang and W. C. I. Wu, "Digital storytelling for enhancing student academic achievement, critical thinking.; Learning motivation: A year-long experimental study," Comput. Educ., vol. 59, no. 2, pp. 339-352, 2012, doi: 10.1016/j.compedu.2011.12.012.

[35] B. Šumak and A. Šorgo, "The acceptance and use of interactive whiteboards among teachers: Differences in UTAUT determinants between pre- and post-adopters," Comput. Human Behav., vol. 64, pp. 602-620, 2016, doi: 10.1016/j.chb.2016.07.037. 
[36] M. Limayem, S. G. Hirt, C. M. K. Cheung, and S. G. Hirt, "How habit limits the predictive power of intention: The case of information system continuance," MIS Q., vol. 31, no. 4, pp. 705-737, 2007.

[37] A. Tesser, D. Whitaker, L. Martin, and D. Ward, "Attitude Physiological Attitude Change and," J. Pers., vol. 24, no. I, pp. 89-96, 1998.

[38] F. M. Zain, E. Hanafi, Y. Don, M. F. M. Yaakob, and S. N. Sailin, "Investigating student's acceptance of an EDMODO content management system," Int. J. Instr., vol. 12, no. 4, pp. 1-16, 2019, doi: 10.29333/iji.2019.1241a.

[39] M. A. Yeop, M. F. M. Yaakob, K. T. Wong, Y. Don, and F. M. Zain, "Implementation of ICT policy (blended learning approach): Investigating factors of behavioural intention and use behaviour," Int. J. Instr., vol. 12, no. 1, pp. 767-782, 2019, doi: 10.29333/iji.2019.12149a.

[40] T. Teo, C. B. Lee, and C. S. Chai, "Understanding pre-service teachers' computer attitudes: Applying and extending the technology acceptance model," J. Comput. Assist. Learn., vol. 24, no. 2, pp. 128-143, 2008, doi: 10.1111/j.1365-2729.2007.00247.x.

[41] T. Teo and J. Noyes, "An assessment of the influence of perceived enjoyment and attitude on the intention to use technology among pre-service teachers: A structural equation modeling approach," Comput. Educ., vol. 57, no. 2, pp. 1645-1653, 2011, doi: 10.1016/j.compedu.2011.03.002.

[42] S. S. Liaw, H. M. Huang, and G. D. Chen, "Surveying instructor and learner attitudes toward e-learning," Comput. Educ., vol. 49, no. 4, pp. 1066-1080, 2007, doi: 10.1016/j.compedu.2006.01.001.

[43] M. K. O. Lee, C. M. K. Cheung, and Z. Chen, "Acceptance of Internet-based learning medium: The role of extrinsic and intrinsic motivation," Inf. Manag., vol. 42, no. 8, pp. 1095-1104, 2005, doi: 10.1016/j.im.2003.10.007.

[44] E. Tarcan, E. S. Varol, and B. Toker, "A Study on the Acceptance of Information Technologies from the Perspectives of the Academicians in Turkey," Ege Akad. Bakis (Ege Acad. Rev.), vol. 10, no. 3, pp. 791-791, 2010, doi: 10.21121/eab.2010319615.

[45] C. M. Ringle, M. Sarstedt, R. Schlittgen, and C. R. Taylor, "PLS path modeling and evolutionary segmentation," J. Bus. Res., vol. 66, no. 9, pp. 1318-1324, 2013, doi: 10.1016/j.jbusres.2012.02.031.

[46] J. F. Hair Jr, G. T. M. Hult, C. Ringle, and M. Sarstedt, A primer on partial least squares structural equation modeling (PLS-SEM). Sage Publications, 2016.

[47] J. C. Anderson and D. W. Gerbing, "Structural equation modeling in practice: A review and recommended two-step approach," Psychol. Bull., vol. 103, no. 3, p. 411, 1988.

[48] C. M. Ringle, S. Wende, and J.-M. Becker, "SmartPLS 3," Boenningstedt SmartPLS, 2015. [Online]. Available: http://www.smartpls.com.

[49] J. F. Hair, J. J. Risher, M. Sarstedt, and C. M. Ringle, "When to use and how to report the results of PLS-SEM," Eur. Bus. Rev., vol. 31, no. 1, pp. 2-24, 2019, doi: 10.1108/EBR-11-2018-0203. 